Session: 2330

\title{
Graduate Engineering Student Performance Assessment: How learning pattern affects test scores
}

\author{
Timothy Chang, New Jersey Institute of Technology, NJ \\ and \\ Daphne Chang, Bloomfield College, NJ
}

\begin{abstract}
In this paper, the findings based on a graduate electrical engineering course titled "RealTime Control Systems Design" are analyzed and reported. This course comprises of a lecture and laboratory component where the students are expected to transform their theoretical knowledge into a viable team laboratory design and present the results to the entire class. Upon running this course for seven consecutive years, the following observations are, invariably, made:

1. A bimodal distribution exists between theory and experiment: Students achieving the best classroom scores do not always perform well in a free structure designbased experimental project. Similarly, students who rank in the lower quartile for classroom performance may excel in the experimental project.

2. Composition of team members significantly affects the quality of the experiment. Standard indicators such as GPA do not strongly correlate with the experimental outcome.

3. Strong classroom participation does not correlate with overall course success.

Administering the Myers-Briggs Type Indicator during the last two years provided an extra analytical dimension. From the MBTI test data and course grades, it is concluded that the "learning patterns" play a significant role in student performance and specifically, in relations to issues 1-3 above. Based on the combined results, a number of recommendations are brought forth for improving curriculum design and student assessment at the graduate level.
\end{abstract}

\section{Introduction}

Engineering differs from most other education fields in that the graduates are expected to be able to transform their classroom experience into the industrial environment which requires critical thinking, design abilities, team-work, management skills; in additional to fundamental scientific/engineering knowledge. The definition of a qualified graduate, from the educational institute's perspective, should reflect the student's ability to thrive 
in the industry. Standard classroom evaluation is heavily based on individual paper accomplishments: assignments, quizzes, exams, term projects, etc. While these are effective measures, a serious gap remains in assessing the student's ability with respect to the abovementioned industrial criteria. Traditionally, graduate engineering education appeals to a focused group of candidates: those who wish to pursue an R\&D career. However, with the changes in technological integration, a master's degree is now almost a necessary requirement for professional competitiveness and growth across all electrical engineering (EE) subfields. The influx of "non-traditional students" into the EE Master degree program poses special challenge to the curriculum design and student assessment processes which are further affected by the following conditions:

- EE graduate level courses are theoretically oriented with little or no experimental work.

- Assessment is dominantly based on assignments, examinations, and "paper" projects.

- Thesis is no loner required and most students choose the course-only option.

- Part-time students constitute a majority of the student body.

Over the past decade, many observations and comments about the changing characteristics of graduate students, especially at the master's level, have been made. Specifically, it is generally considered that the students are not as "good" as they used to be. However, It has also been observed that the best students, in terms of indicators such as GPA, are not always the ones to excel in their careers.

The central issues facing academic institutions are then:

- How to assess student performance with respect to broad-spectrum academic/industry benchmark.

- How to provide a learning environment so that the students can realize their full career potential.

- How to improve team-work and communication skills.

This paper discusses the summary analysis of an electrical engineering graduate course titled "Real-time Control Systems". This course has been offered to graduate students from electrical engineering, mechanical engineering, and computer science since 1992. Although control systems have a wide range of engineering applications, e.g. aerospace, chemical, civil \& transportation, manufacturing, mechanical, power, etc., graduate level control systems courses are usually presented in a highly mathematical and theoretical manner; thereby filtering out a large population of students who are more experiment oriented. "Real-time Control Systems ", on the other hand, comprises of a theoretical component and an experimental component: the students are required to team-up, design/construct a motion control experiment, and apply control systems theory knowledge from the lectures so as to meet the performance specifications of the experiment. Finally, the students are evaluated on their knowledge of theory (assignments and exams) and experimental projects.

Over the years, a widening decorrelation between theoretical and experimental 
performances is observed with the class grades resulting in a bimodal distribution. Preliminary analysis quickly revealed that this decorrelation trend has less to do with gender, ethnicity, or the average GPA of the class. Rather, the trend is a result of a diversifying graduate student body whose profile bears closer resemblance to undergraduate cohorts than to the traditional graduate ones.

In order to further analyze this trend, a number of psychological test instruments have been considered and it was determined that the Myers-Briggs Type Indicator (MBTI) was the most appropriate. A brief discussion of the MBTI is given in Section 3 of this paper.

A number of results describing the role of MBTI in engineering education have been reported. For example, the use of MBTI in curriculum analysis and design was discussed in [1]. In [2] experimental confirmation of the relationship between MBTI, various psychometric factors, and categories of cognitive activities was obtained. MBTI was also used as a part of a profile analysis to predict student performance in a first year chemical engineering course [3] . In [4] the use of MBTI for team formation was discussed.

In [5] a group problem-solving model, based on MBTI, was introduced to address student deficiencies in problem solving skills and teamwork. MBTI was used to predict academic success and subsequent career satisfaction for engineering students in [6]. In [7], the authors used MBTI as part of a student portfolio for biological engineering students to initiate student-centered learning.

\section{Course description}

The course chosen for analysis is a graduate level automatic control systems course titled: Real-time Control Systems. The reason for choosing a graduate level course (instead of an undergraduate course) is because the characteristics of EE graduate students tend to be more stable: students with low GPAs or poor motivation have already been eliminated. As with other electrical engineering graduate courses, real-time control deals with application of theory to real world problems. Although the common approach is classroom dissemination, this course is designed with an experimental component for the following reasons:

- To provide the students with better understanding of the application through handson experience.

- To motivate the students by challenging them to compete with each other.

- To improve teamwork and communication skills.

The experiment is free-structure where each team, consisting of two to three students, is given an Airpax DC motor, an LM675 high current operational amplifier, and small machine tools. The goal is to design, build, and control a single link robot arm to rotate a 50 gram load with a radius of $10 \mathrm{~cm}$ to 90 degrees $+/-1$ degree with less than $25 \%$ overshoot and in minimum time, while holding the load in that position for at least two minutes. Block diagram of the single link robot arm system is show in Figure 1 whereas 
the control system block diagram is shown in Figure 2. The students are free to design and implement the hardware platform, sensors, and control software.

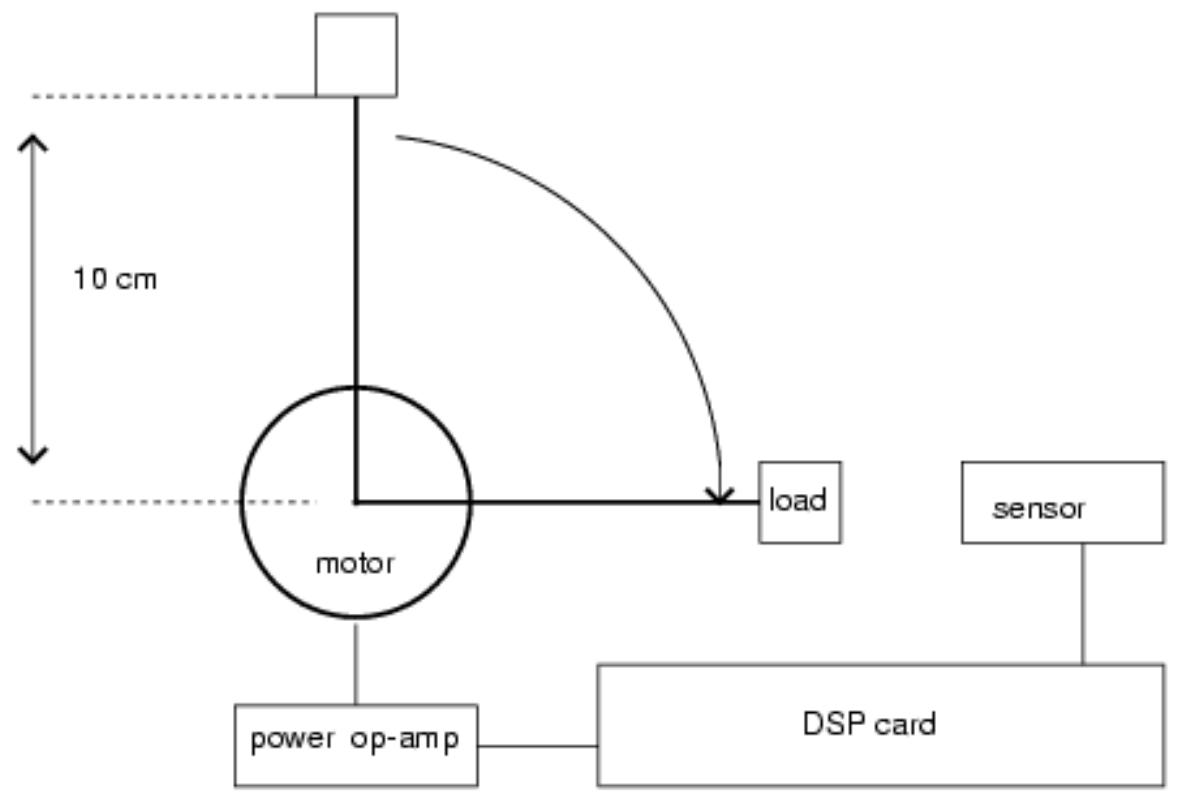

Figure 1. Block Diagram of the Single Link Robot Arm.

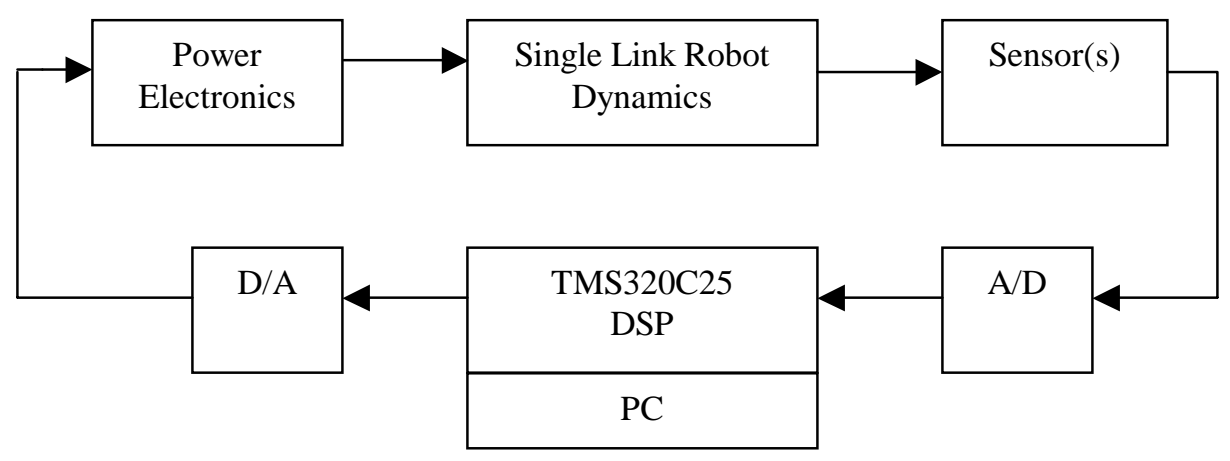

Figure 2. Block Diagram of the Experimental Control Systems 
The grading scheme for the experimental component is based on:

$20 \%$ Hardware design and build quality

25\% Experimentation and data

$10 \%$ Innovation and creativity

$30 \%$ Analysis and discussions

$10 \%$ Presentation and communication skills

5\% Documentation

At the end of the semester, each team is allocated a 20 minutes time slot to present their project and an additional 5 minutes for Q\&A. Each team member is evaluated separately, although the grades are generally correlated within each team.

The lecture materials are designed to mesh with the experiment. An outline of the course is shown below:

Week Topics

1 Introduction to real-time control systems

2 Architecture of DSP systems: the TMS320C25

3 Programming the $\mathrm{C} 25$

$4 \quad \mathrm{~A} / \mathrm{D}, \mathrm{D} / \mathrm{A}, \mathrm{PLA}$, and other peripherals

5 Properties of sampled-data systems

$6 \quad$ Properties of sampled-data systems (cont'd)

7 Review of Z-transform

8 Mid-term Examination

9 Digital controller design I: Parameter optimized controllers

10 Digital controller design II: State controllers

11 Digital controller design IIII: Feedforward and cancellation controllers

12 Translation of analog designs

13 Practical issues: sampling rate,dead-time, scaling, reset windup, etc.

14 Experiment/project presentation

15 Final Exam

The lecture grading scheme is based on homework, a mid-term and a final examination.

\section{Myers-Briggs Type Indicator and its applications in engineering education}

The MBTI Personality Inventory is based on Jung's theory indicating how the interactions among the preferences of perception and judgment (mental functions) and 
attitudes of orientation toward external world would result in 16 distinctive personality types. The MBTI is most often used by educators to identify students' learning styles, by student development professionals to provide career guidance and to improve student retention, as well as by management consultants to develop leadership and group dynamic/ teamwork training among employees.

The MBTI Personality Inventory identifies two opposite preferences for each of the four scales. 1) the EI scale, where does one prefers to focus one's attention? People who prefer extraversion tend to direct energy in the outer world, communicate more by talking, like action and variety. People who prefer introversion tend to be reflective observational learning type, like lecture format. 2) the SN scale, how does one acquire information? Sensing type tends to have concrete experiential learning and/or abstract sequential learning styles with high factual retention. Intuitive type, on the other hand tends to be abstract conceptual learner, high in academic comfort, reflective judgment and likes self directed learning. 3) the TF scale: how does one make decisions or draw conclusions? Thinking types tend to be both abstract conceptual and sequential learner and have a talent for analyzing a problem or situation. Feeling types tend to be concrete experiential learner and/or abstract random learner. 4) the JP scale, how does one orient toward the external world? Those who prefer judging tend to be abstract conceptual learner, like structure and motivation in learning, high in fact retention and academic comfort. Those who prefer perceiving are more likely to show concrete experiential learning style, active experiential learning and collaborative learning.

According to [9], the SPs and the SJs each comprise roughly 38 percent of the population in the United States, while the NTs and the NFs comprise 12 percent of the population respectively. In this study sample, there are $6 \mathrm{NTs}, 1 \mathrm{NF}, 15$ SJs and 5 SPs. SJ types (55\% of this study) are often labeled as "good student" in academic setting because they valued hard work and demonstrated dependability. They do better in theory class when they can follow outlines and if the teacher pointed out how the theory apply to the real world before class. The research indicates that as long as what they are studying are facts or procedures, they are comfortable. For the SJs to speculate, invent, or improve, they often fail to deliver satisfactory performance despite their studious dependability. SP types (19\% of this study, despite its $38 \%$ representation in general population) are least represented in higher education and tend to have lowest correlation between academic ability and GPA. NT types (22\% of this study) are largely represented in science and engineering fields.

A successful engineering professional in the twenty-first century requires a commitment for life long learning, quality of teamwork spirit and ability for project management. MBTI Inventory results provide individuals with avenues for self-awareness and possibilities for human growth and professional development. To respond to the popular request for accountability in higher education and partnerships with business community the graduate engineering programs are encouraged to design curriculum that would address these concerns. The MBTI Inventory could be one of the instruments that the educators can adopt to better prepare future engineers with both technical skills, 
knowledge and professional qualities to meet the market demands.

Applying the MBTI typology in graduate engineering classes will enable educators to accomplish the following benefits:

- Develop curriculum to support and challenge each types.

- Facilitate the learning process of team project by recognizing individual strengths and introducing the elements of complementary working styles among opposite types.

- Adopt desirable assessments, a holistic approach, that warrant adequate evaluations of student performance.

As for engineering students, they would gain better insights regarding their learning style and obtain optimum learning outcomes. In addition to recognize their individual strengths, they are given the opportunities to develop competencies in the areas that are perceived as their weaknesses. With this knowledge, the authors hope to instill selfconfidence among engineering students and to challenge students intentionally learning the skills that are in less functioning areas.

Last but not least, using MBTI Inventory can be one of the strategies to address issues on academic persistence and student retention. Any effort in acknowledging individual differences and in improving supports for various learning types will definitely enhance academic comfort among at risk students and hence increase college retention.

\section{Course data and analysis}

Since 1992, EE664 Real-time Control Systems is given at every fall semester with environment restricted to 15. MBTI was administered to the class of 1997 and 1998 for detailed analysis. Along with the MBTI, other relevant data include: theory grades (based on written tests), experiment grades, and individual GPA.

\section{(A) MBTI type distribution}

The distribution is summarized in Table 1 below where the 16 types are arranged in a 4by-4 matrix. Three sets of data are listed: CAPT/MBTI, 1997/EE664, and 1998/EE664. CAPT/MBTI represents data from Center for Applications of Psychological Type-MBTI data Bank for undergraduate electrical/electronics engineering students. 1997/EE664 and 1998/EE664 are the data collected from the 1997 and 1998 classes respectively. It is observed the type distributions of the 1997 and 1998 classes correlate well with the CAPT/MBTI data. It is further noted that, for the two classes:

- S_J types constitute the most significant core of the student body (38\% for 1997 and $69 \%$ for 1998).

- I to E ratio varies from 3.8 for 1997 to 2.1 for 1998.

- The students are dominantly $\mathrm{T}$ type. 
Table 1. MBTI Distribution

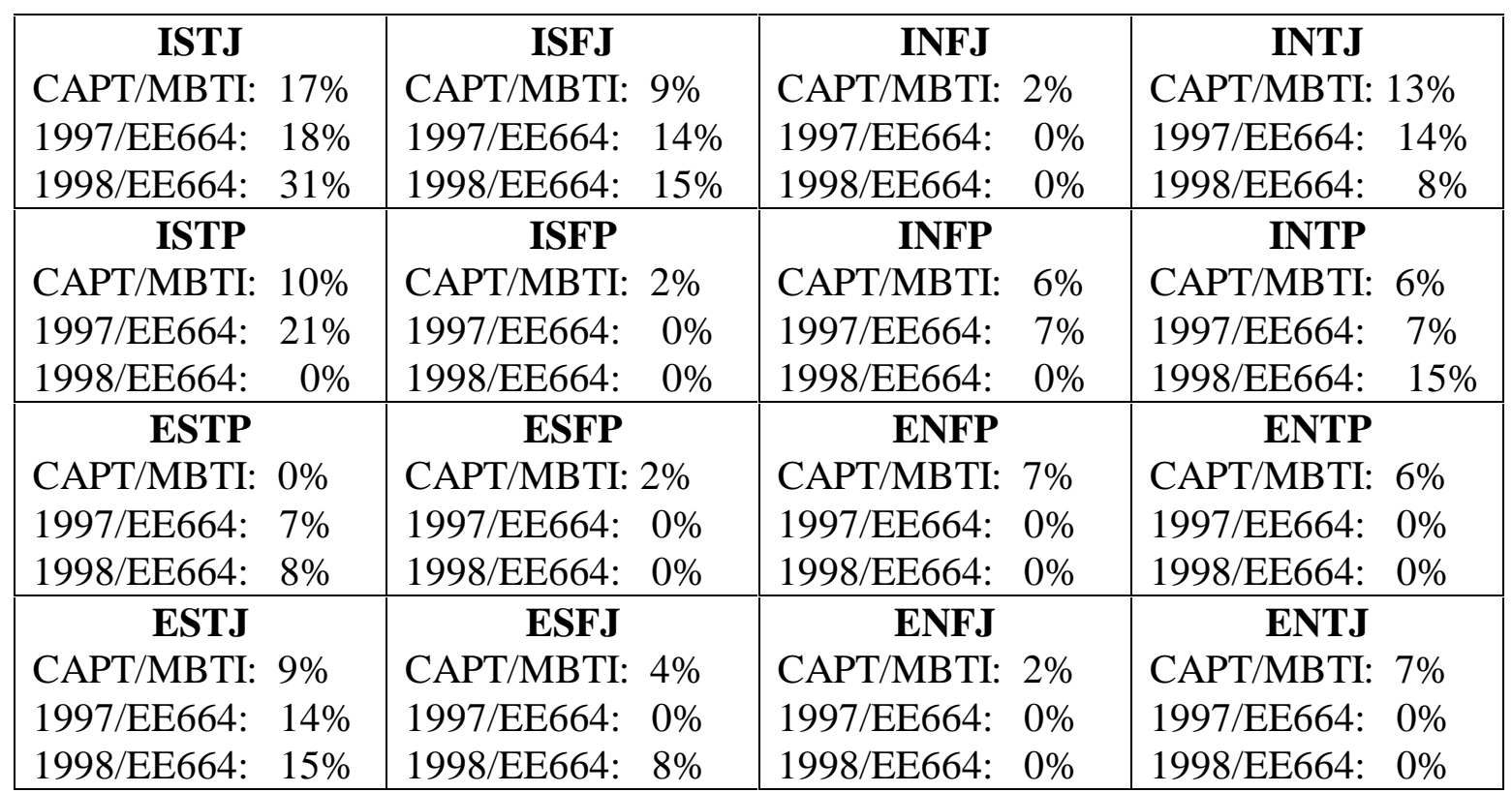

(B) Class data

Four sets of data are compiled: theory grades, experimental grades, combined grades (using a 60-40 weighting for theory and experiment), and cumulative GPA. All scores are normalized to $100 \%$. For the 1997 class, the bar graphs and the composite plots (with GPA) are shown in Figures 3-4 while the box plots are shown in Figure 5. Similarly, for the class of 1998, the bar graphs and the composite plots (with GPA) are shown in Figures 6-7 while the box plots are shown in Figure 8. By plotting the GPA curve along with theory, experimental, and combined curves, a visual indication of the correlation of the curves is obtained. The box plots, on the other hand, provides information such as lower quartile, median, and upper quartile values. The notches represent a robust estimate of the uncertainty about the means.

For the 1997 class, it is observed that:

1. The best theory grades are scored by ISFJ, ISTP, ESTJ, ISFJ types.

2. The experimental grades are scored by the team with INFP, INTJ, ISTJ members.

3. The lowest theory grades are scored by P type students while the lowest 
experimental grades scored by S_P and S_J type students.

4. From Figure 4, it is noted that the GPA curve correlates very well with the Theory curve (correlation coefficient $=0.63$ ). On the other hand, the experimental grades correlate poorly with the GPA curve (correlation coefficient $=0.1$ ). This is perhaps not surprising since the GPA reflects mostly structured, classroom performance.

5. As a result of combining theory grades (60\%) and Experiment grades (40\%), two "theorists" (ISTP, ISFJ) suffer overall grade reduction (from using theory grades alone) while two $\mathrm{N}$ type students obtain grade boost.

6. E type students tend to be more visible and vocal in class. However, this stronger classroom participation does not translate into noticeable performance gain in either theory or experiment.

For the 1998 class, similar observations are made:

1. Best Theory grades: ESTJ, INTJ, ISFJ ISTJ.

2. Best experimental grades: team with INTP, ISTJ, INTJ members.

3. Lowest Theory grades: ESFJ, ESTJ, INTP. Lowest experiment grades: Team with ISTJ, ISTJ, ISTJ members.

4. From Figure 7, correlation between the GPA curve and Theory Curve is high (correlation coefficient 0.74 ) while correlation with experiment is lower (correlation coefficient $=0.48$ ).

5. As a result of combining Theory and Experiment grades, one student (ESTJ) suffer from grade reduction while three others (INTP, ESFJ, ESTJ) receive grade boost. It should be mentioned that the INTP student performs the best experiment and therefore receives the biggest boost. The two ES_J students have low grades to begin with and have benefited from the team nature of the experimental work.

6. Performance slightly correlates with I type instead of the more "active" E type.

(C) Discussions and Recommendations

From the above data, it is observed that the two classes exhibit similar characteristics in terms of MBTI distributions, GPA, Theory and Experiment performances. The most notable feature is that Experimental abilities (for free-structure experiments that require innovation and creativity), the N-type students consistently outperform the other types. However, this ability is not reflected in their GPAs since almost all graduate EE courses are theory-based. The $\mathrm{S} \_J$ type students thrive in a highly structured environment (i.e. good standard classroom performance) but are less apt to doing a "real" engineering project. The $\mathrm{P}$ type is more problematic (with respect to the EE curriculum) in that they tend to procrastinate and leave many loose ends. Finally, it is further observed that team with a mix of $\mathrm{N}$ type and $\mathrm{S} \_\mathrm{J}$ tend produce the best experimental results as they are complementary to each other.

Even though the statistics in this paper is limited, the consistency of data trend nevertheless warrants the following recommendations: 
- Reconsider assessment criteria for Master level EE students. More emphasis should be placed on experimental projects, team-work, and communication skills.

- MBTI should be used in helping students to modify their work habit and to form teams with complementary types.

- Particular attention should be paid to the F and P type students who tend to experience difficulties in EE program.

- Design curriculum and program to accommodate and challenge students of different types.
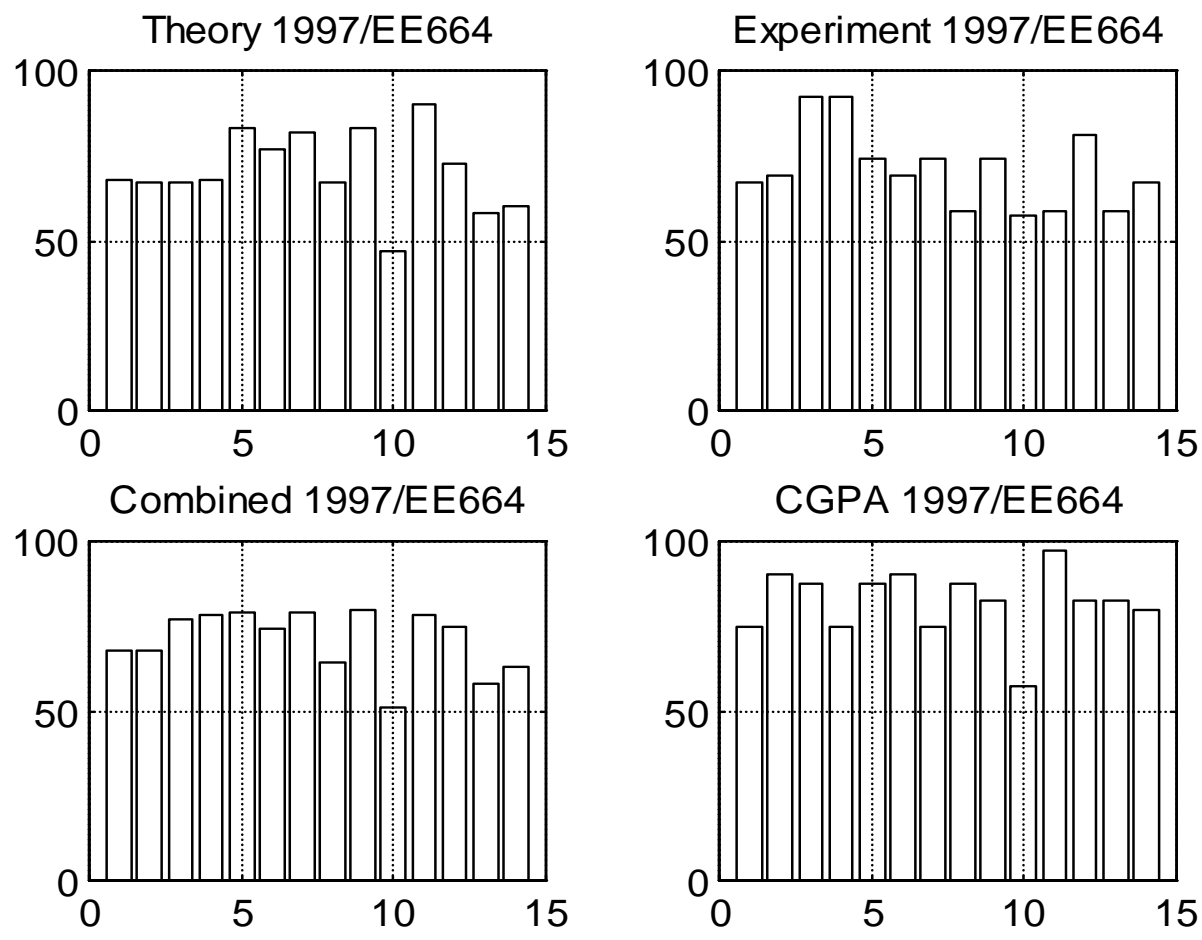

Figure 3 Bar Graph of 1997/EE664 Data 
Theory and GPA 1997/EE664

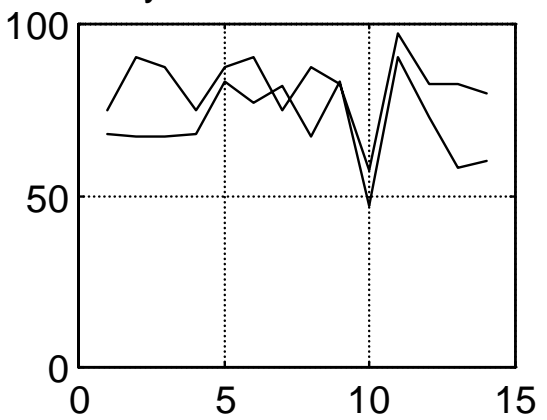

Combined and GPA 1997/EE664

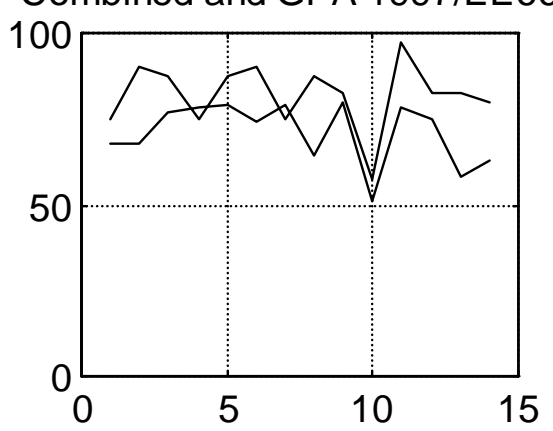

Experiment and GPA 1997/EE664

100

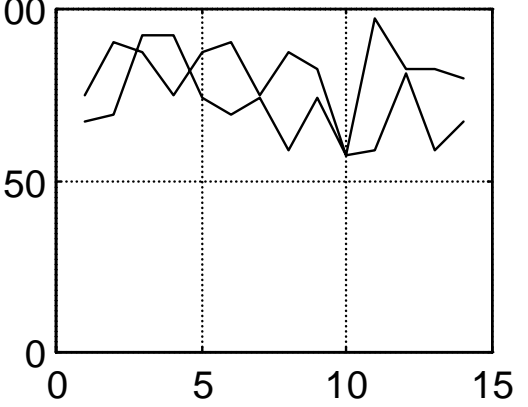

Figure 4 Composite Plot for 1997/EE664 Class
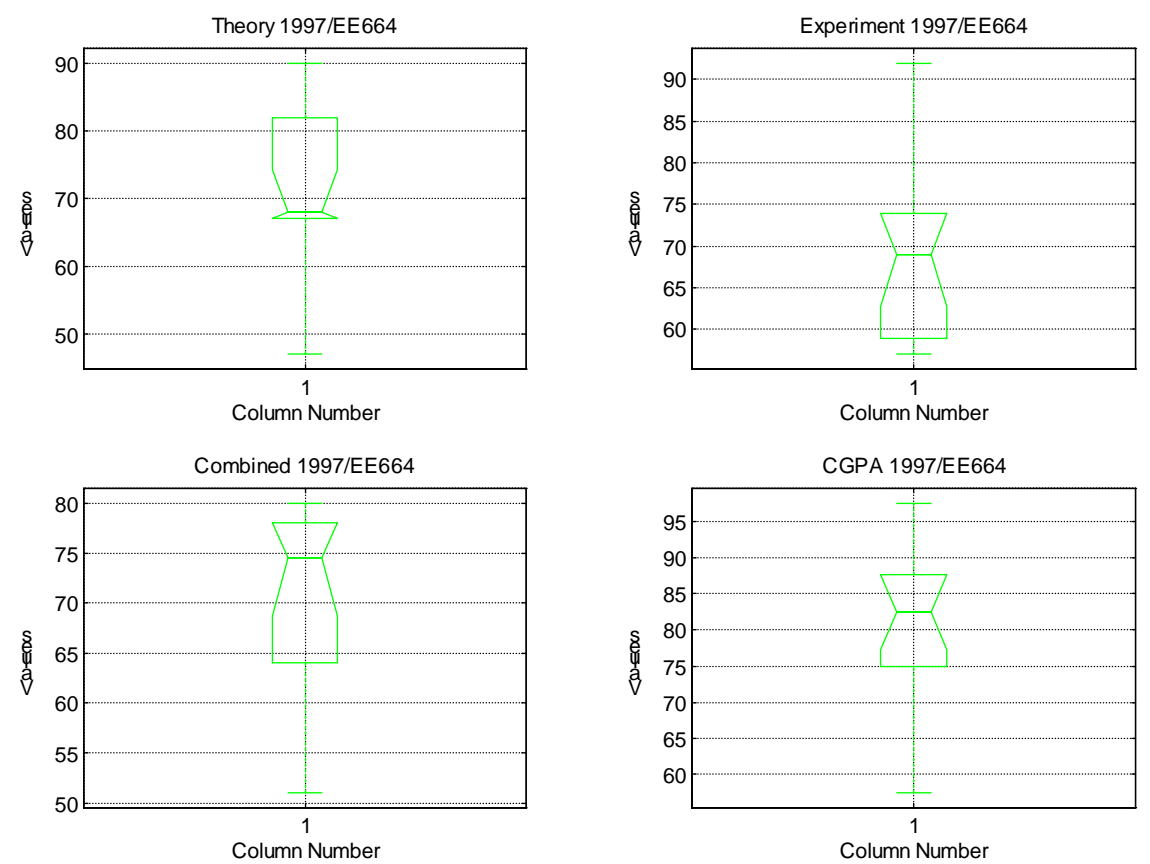

Figure 5 Box Plot for 1997/EE664 Data 

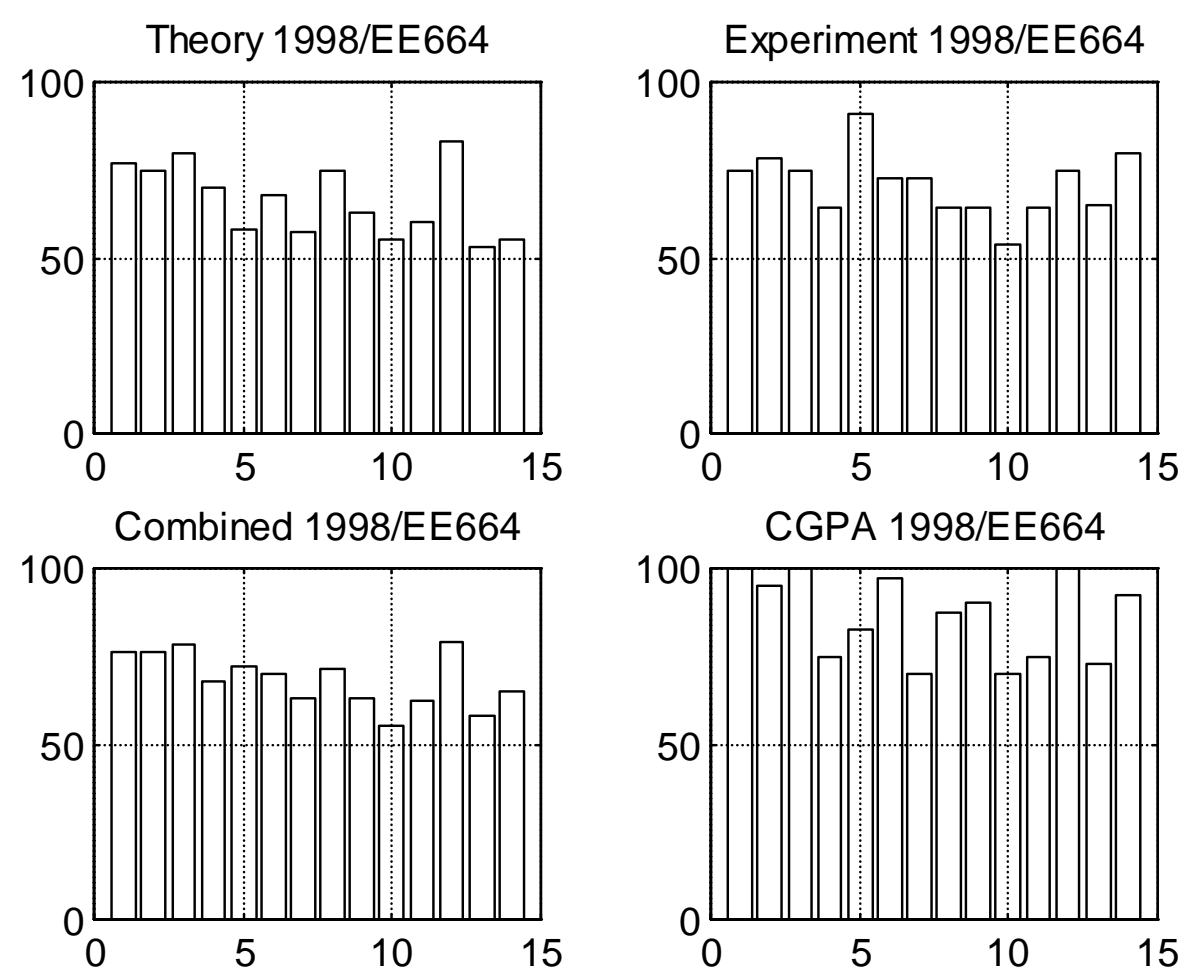

Figure 6 Bar Graph of 1997/EE664 Data

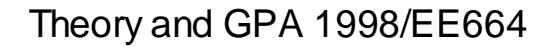

Experiment and GPA 1998/EE664
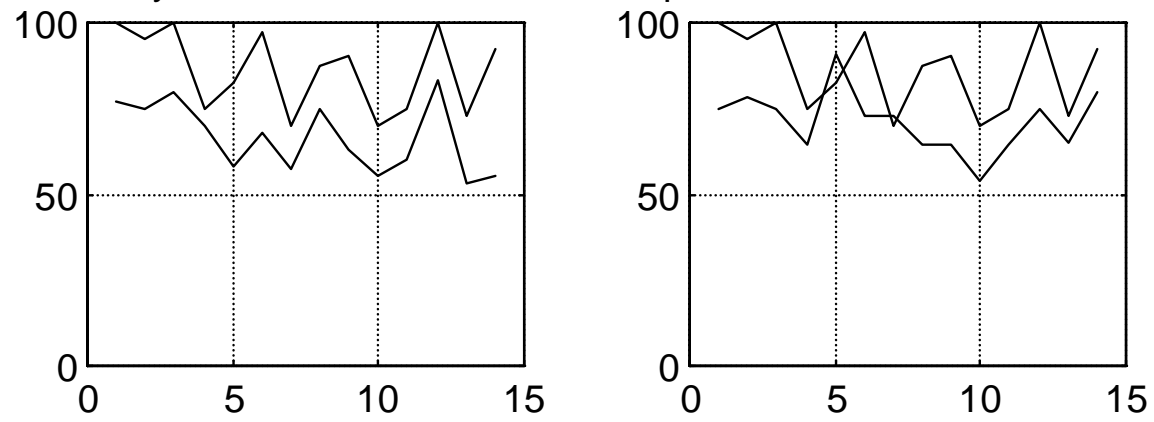

Combined and GPA 1998/EE664 Theory and Experiment 1998/EE664
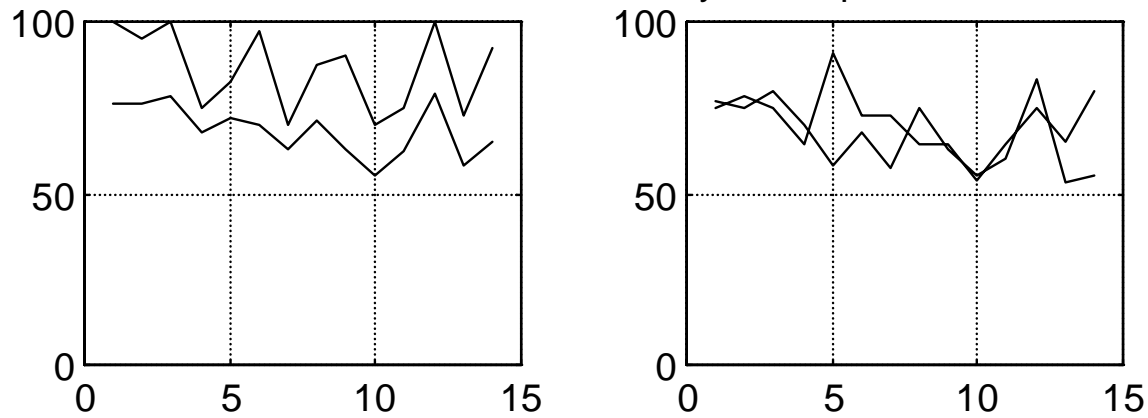

Figure 7 Composite Plots of 1998/EE664 Data

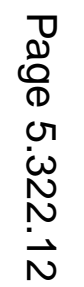



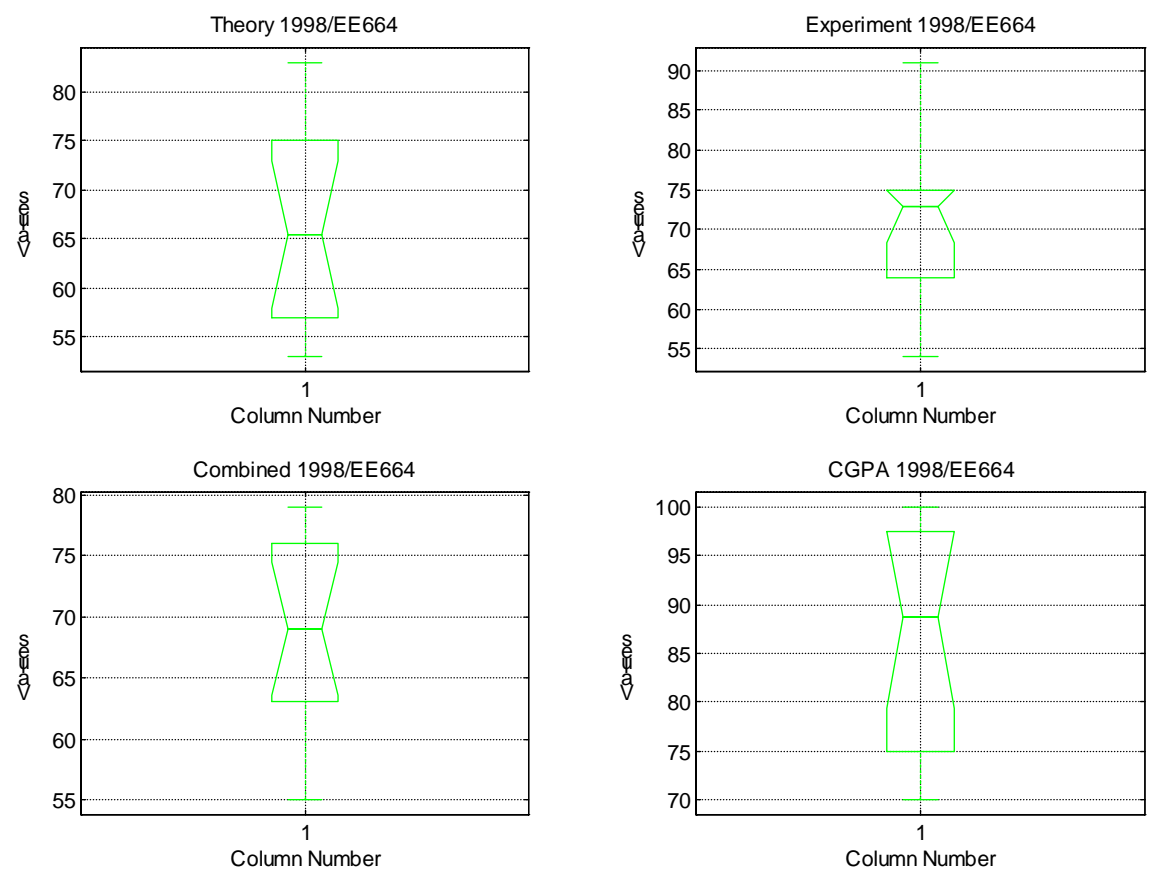

Figure 8 Box Plot of 1997/EE664 Data

\section{Conclusions}

This paper describes the data and analysis of performance assessment for a master level electrical engineering course titled: "Real-time Control Systems". In the seven years history of this course, it was frequently noted that the theory and experiment grades did not correlate well. In order to help analyze this discrepancy, the Myers-Briggs Type Indicator inventory was administered to the class of 1997 and 1998. The results provided an extra analytic dimension and led to the conclusion that psychological types play an important role in student "performance" in (1) a highly structured classroom environment and (2) a free-structure experimental project. Traditional graduate assessment criteria heavily biased towards the classroom environment so that students with excellent hands-on and creative skills are not evaluated adequately. Given that a master degree is becoming a necessary requirement for practicing engineers, a broad based assessment mechanism that include analytic ability, creativity, hands-on ability, and communication skills should be devised and implemented.

References

[1] Staiger, Eugene H., "CURRICULUM REDESIGN: PSYCHOLOGICAL FACTORS WORTH," Frontiers in Education Conference Oct 15-17 1989 1989, pp 140-144.

[2] Carpenter, Raymond A.; Bishu, Ram R.; Riley, Michael W., "USER CHARACTERISTICS. ARE PERSONALITY TYPES AND PSYCHOMETRIC FACTORS GOOD PREDICTORS?" Proceedings of the Human Factors Society 34th Annual Meeting - Orlando 90 Oct 8-12 1990, pp 351-355. 
[3] Felder, Richard M.; Forrest, Krista D.; Baker-Ward, Lynne; Dietz, E. Jacquelin; Mohr, Phyllis H., "LONGITUDINAL STUDY OF ENGINEERING STUDENT PERFORMANCE AND RETENTION: I. SUCCESS AND FAILURE IN THE INTRODUCTORY COURSE," Journal of Engineering Education v 82 n 1 Jan 1993 pp. 15-21.

[4] Parsons, J. Roger; Klukken, P. Gary, "INTRODUCTORY DESIGN AND INNOVATION COURSE AT THE UNIVERSITY OF TENNESSEE," Proceedings of the 1995 25th Annual Conference on Frontiers in Education. Part 1 (of 2) Nov 1-4 1995 v1 1995 Atlanta, GA, , USA, pp. 442-444 .

[5] Daigle, R.J.; Doran, Michael V.; Pardue, J. Harold, "INTEGRATING COLLABORATIVE PROBLEM SOLVING THROUGHOUT THE CURRICULUM," Proceedings of the 1996 27th SIGCSE Technical Symposium on Computer Science Education Feb 15-18 19961996 Philadelphia, PA, USA, pp. 237-241.

[6] Rosati, Peter, "STUDENTS' PSYCHOLOGICAL TYPE AND SUCCESS IN DIFFERENT

ENGINEERING PROGRAMS," Proceedings of the 1997 27th Annual Conference on Frontiers in Education. Part 2 (of 3) Nov 5-8 1997 v2 1997 Pittsburgh, PA, USA, pp. 781-784.

[7] Christy, Ann D.; Lima, Marybeth, "USE OF STUDENT PORTFOLIOS IN ENGINEERING INSTRUCTION," Journal of Engineering Education v 87 n 2 Apr 1998 ASEE Washington DC, USA, pp. 143-148.

[8] Jensen, Daniel D.; Murphy, Michael D.; Wood, Kristen L, "EVALUATION AND REFINEMENT OF A RESTRUCTURED INTRODUCTION TO ENGINEERING DESIGN COURSE USING STUDENT SURVEYS AND MBTI DATA," Proceedings Proceedings of the 1998 Annual ASEE Conference Jun 28Jul 119981998 Seattle, WA, USA, pp 1049-1052.

[9] Keirsey, D.; Bates, M. (1984), "Please Understand Me: Character \& Temperament Types". Del Mar, CA: Prometheus Nemesis Book Company.

\section{TIMOTHY CHANG}

Timothy Chang is an Associate Professor of Electrical \& Computer Engineering at the New Jersey Institute of Technology. He received his B.Eng. (hon) degree from McGill University, his M.A.Sc. and Ph.D. degrees in Electrical Engineering from University of Toronto. Prior to joining the faculty of NJIT, Dr. Chang was a Senior Research Specialist and a Program Manager at Kearfott Guidance \& Navigation Corp. He received the Best Teaching Assistant Award from University of Toronto in 1986, the NJIT Excellence in Teaching Award in 1997, Provost's Challenge to Innovative Teaching Award in 1999, and the NJIT College of Engineering Excellence in Teaching Award in 2000. He is the PI or Co-PI of several federal and state grants, including a \$400K NSF CRCD Program in Optical Science and Engineering, a $\$ 10.2$ million NIST ATP grant on Precision Optoelectronics Assembly. Dr. Chang is the Chair of the North Jersey IEEE Control Systems Chapter and the IEEE Student Branch Advisor at NJIT.

Daphne Chang

Ms. Daphne Chang is an Assistant Director for Career Development at Bloomfield College. In addition to providing career counseling and assessments, she also teaches career planning seminar course. Since 1994, Ms. Chang has been using MBTI Personality Inventory in her classes to enhance personal awareness and to facilitate career development among college students. She holds an M.A. in Curriculum Development from the University of Kansas and an M.Ed. in Adult Counseling \& Education from University of Toronto. Currently, Ms. Chang is a board member of Middle Atlantic Career Counseling Association. 